\title{
Analysis of the 5'UTR of HCV genotype 3 grown in vitro in human B cells, T cells, and macrophages
}

\author{
Dennis Revie1, Michael O Alberti1,5, John G Prichard², Ann S Kelley ${ }^{3}$ and S Zaki Salahuddin*4
}

\begin{abstract}
Background: Previously, we have reported the isolation and molecular characterization of human Hepatitis $C$ virus genotype 1 (HCV-1) from infected patients. We are now reporting an analysis of HCV obtained from patients infected with HCV genotype 3 (HCV-3) as diagnosed by clinical laboratories.

Results: HCV was cultured in vitro using our system. HCV RNA was isolated from patients' blood and from HCV cultured in various cell types for up to three months. The 5'UTR of these isolates were used for comparisons. Results revealed a number of sequence changes as compared to the serum RNA. The HCV RNA produced efficiently by infected macrophages, B-cells, and T-cells had sequences similar to HCV-1, which suggests that selection of the variants was performed at the level of macrophages. Virus with sequences similar to HCV-1 replicated better in macrophages than HCV having a 5'UTR similar to HCV-3.

Conclusions: Although HCV-3 replicates in cell types such as B-cells, T-cells, and macrophages, it may require a different primary cell type for the same purpose. Therefore, in our opinion, HCV-3 does not replicate efficiently in macrophages, and patients infected with HCV-3 may contain a population of HCV-1 in their blood.
\end{abstract}

\section{Background}

$\mathrm{HCV}$ is associated with a number of diseases, including hepatocellular carcinoma, B-cell lymphomas, and neuropathy. There is an emerging list of diseases that may have some association with this virus. Approximately $8 \%$ of HCV-infected individuals in the United States are infected with genotype 3 [1]. The chances of liver damage due to $\mathrm{HCV}$ infections may not vary by genotype in untreated individuals [2,3], and infections with $\mathrm{HCV}-3$ are more likely to respond earlier to ribavirin $/ \alpha$-interferon combination therapy than HCV-1 [3-5]. There is evidence that individuals infected with HCV-3 are likely to progress rapidly to liver steatosis [6], and fibrosis [7] compared to infection with HCV-1. Individuals infected with $\mathrm{HCV}$ are also frequently infected with other viruses. Hematopoietic cells e.g., HCV infected T-cells, are capable of being co-infected with HIV-1 and HHV-6 [8]. All of the co-infecting viruses continue to replicate in these cells.

Although synthetic constructs are commonly used for HCV related studies, we have a system for studying the

* Correspondence: zaki@cimm.net

${ }^{4}$ California Institute of Molecular Medicine, Ventura, California, USA Full list of author information is available at the end of the article natural virus isolated from infected patients. Reports using constructs viz., Replicon, pseudo-particles etc. may have produced interesting data, but these results lack meaning in the area of human diseases and public health. Meaningful data must come from viruses isolated from patients since no Replicon disease yet exists.

The 5'UTR of HCV controls replication through capindependent translation [9-11]. For this report, HCV was isolated from the blood of patients infected with HCV-3 and transmitted into macrophages, B-cells, and T-cells. The 5'UTR of the progeny viruses was analyzed and compared to the sequences of the HCV RNA found in these patients' sera. In our previous reports, the 5'UTR of HCV-1 isolates from patients was analyzed and compared to $\mathrm{HCV}$ cultured in vitro and minor differences were found between the HCV in the isolates and patients' sera $[12,13]$. This suggested that the virus in culture was similar to that found in patients' blood.

\section{Results}

The data reported here represents the analysis of the 5 'UTR of HCV-3 from three patients (designated samples $314,384,388$ ). Primary and secondary isolates analyzed for the study were cultured in vitro for up to three 
months and compared to the HCV RNA from the patients' sera. The primary isolates are obtained from cultured macrophages. A flow chart of our samples is shown in Figure 1.

\section{Determination of best primer sets for analyses}

For the purposes of this report, we first made degenerate versions of the primers that were used for HCV-1 [12]. These primers were named 9.1a, 9.2a, and 10.1a (Table 1). Although these sets of primers were suitable for some HCV-3 samples (Figure 2B), we were unable to obtain the appropriate reactivity for the remainder of the samples. We therefore designed another set of primers to work with genotypes 1 and 3 (named 8 up and 347 down for the first PCR; 37 up and 318 down for the second PCR). Unlike our HCV-1 samples, we were unable to find a single set of primers and PCR conditions that always worked with all of the HCV-3 samples. By testing different combinations of primers and temperature conditions, we were able to generate PCR fragments for all of our samples (Figure 2 and Table 2).

\section{Comparison of the 5'UTR of HCV from patients' sera and CIMM-HCV}

The first sample of HCV-3 analyzed was from patient 314. Few or no changes in the sequences of the 5'UTR were observed for cultured $\mathrm{HCV}$-1, but 19 changes in the

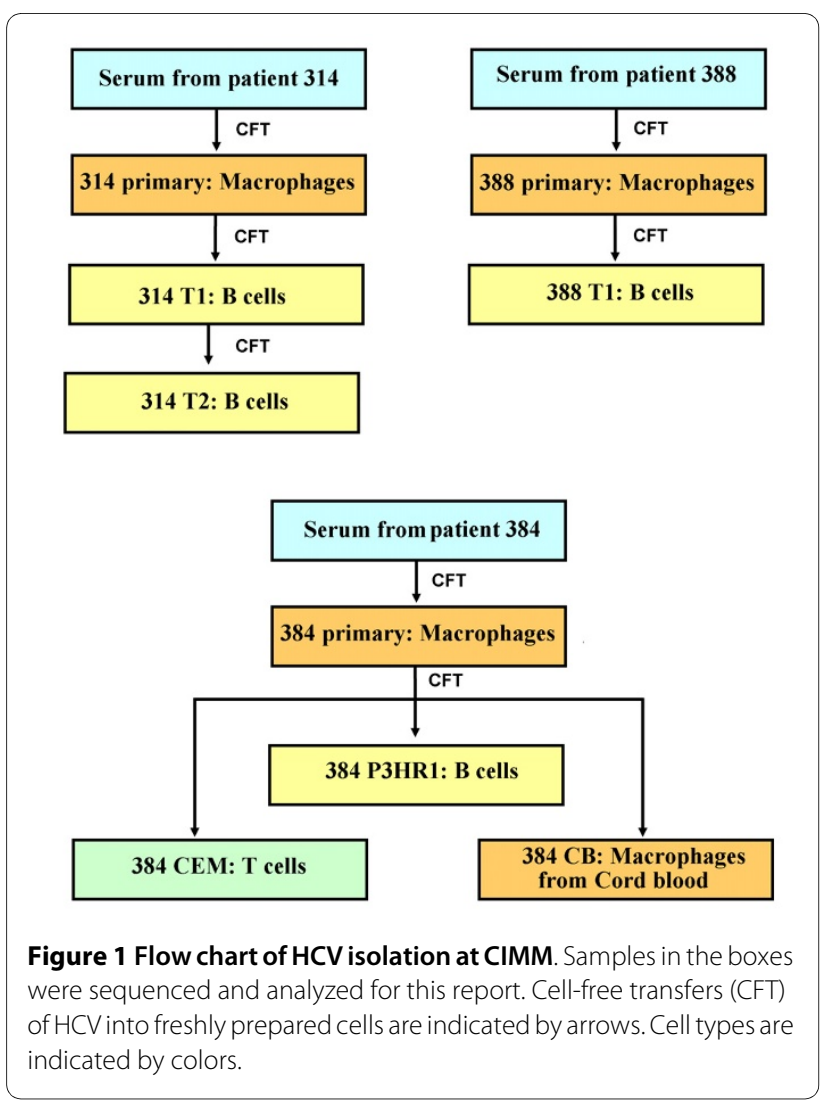

sequences for patient 314 RNA were observed (Figure 3). The sequences for $314 \mathrm{~T} 1$ and $314 \mathrm{~T} 2$ were the same, showing that consecutive transfers of HCV into the same cell type do not affect the sequence. The $314 \mathrm{~T} 1$ and T2 sequences were almost identical to genotype $1 \mathrm{H} 77$, therefore the isolation system for $\mathrm{HCV}-3$ replicated virus which had a 5'UTR similar to HCV-1. This was unexpected, but suggested that there were some $\mathrm{HCV}-1$ in the blood of patient 314 that preferentially replicated in macrophages.

Due to the data from patient $314, \mathrm{HCV}$ was isolated and sequenced from patient 384 . When comparing 384 serum RNA with the four HCV isolates from that serum, there were approximately 17 changes for each isolate (Figure 4), with many of these changes identical to those found in the isolates from patient 314. Furthermore, since there were only small differences between primary isolates (cultured in macrophages) and the secondary isolates (cultured in B-cells and T-cells), the macrophages appear to have selected $\mathrm{HCV}$ with a particular sequence that most closely matched $\mathrm{HCV}-1$. It is possible that patient 384 also had low levels of $\mathrm{HCV}-1$, which was amplified in culture. Although the sequences in the 5'UTR that we are reporting for the isolates were almost identical to H77, we could not amplify the region using our standard primers for $\mathrm{HCV}-1$ samples (9.1a and 9.2a then 10.1a and 10.2, Table 1). It may be that the region upstream or downstream of the reported sequences is similar to $\mathrm{HCV}-3$.

Next, we isolated and sequenced samples from another patient infected with HCV genotype 3: patient 388. Comparing the serum and the isolates did not reveal large changes in the sequence. In fact, the only change observed was an additional $\mathrm{C}$ in a string of C's from bases 121 to 126 for sample 388 T1 (Figure 5). A comparison of sera from patients 314,384 , and 388 revealed that the 388 5 'UTR sequence is actually different from the other two patient serum sequences (Figure 6). Comparisons of the 388 5'UTR sequence and other HCV sequences show that it is similar to the 5'UTR of HCV-1. Therefore, although a clinical lab typed the patient samples as being infected with HCV-3 based on a standard methodology, our results suggest the presence of $\mathrm{HCV}-1$, as well. This may have been a clinical testing error. The sequence found in the macrophages was the same as in the serum.

Other investigators have found that HCV-3 5'UTR sequences direct translation in an in vitro system about as efficiently as $\mathrm{HCV}-1$ sequences [14]. However, a recent report by others compared HCV-1 and HCV-3 5'UTR via Replicons, and showed that $\mathrm{HCV}-3$ versions replicate more slowly in their system than HCV-1 [15]. This agrees with our results that $\mathrm{HCV}$ with genotype 1 sequences preferentially replicate in our system. 
Table 1: List of primers for this study.

\begin{tabular}{|c|c|c|c|c|}
\hline Primer & Strand & Starting position & Ending position & Sequence (5' to 3 ') \\
\hline $9.1 \mathrm{a}$ & Positive & 24 & 42 & GAC ACT CCA CCA TRG ATC ACT C \\
\hline $9.2 \mathrm{a}$ & Negative & 344 & 323 & CAT GWT GCA CGS TCT ACG AGA C \\
\hline $10.1 \mathrm{a}$ & Positive & 48 & 71 & CTG TGA GGA ACT WCT GTC TTC ACG CRG \\
\hline 10.2 & Negative & 310 & 293 & CAC TCG CAA GCA CCC TAT CAG \\
\hline 9.1a-flap & Positive & 24 & 42 & AAT AAA TCA TAA GAC ACT CCA CCA TRG ATC ACT C \\
\hline 9.2a-flap & Negative & 344 & 323 & AAT AAA TCA TAA CAT GWT GCA CGS TCT ACG AGA C \\
\hline 8 up & Positive & 11 & 28 & CCC TGA TGG GGG CGA CAC TCC \\
\hline 347 down & Negative & 345 & 325 & TGC TCA TGG TGC ACG GTC TAC GAG \\
\hline 37 up & Positive & 41 & 66 & CAC TCC CCT GTG AGG AAC TAC TGT CTT CA \\
\hline 318 down & Negative & 316 & 295 & CCG GGG CAC TCG CAA GCA CCC TAT C \\
\hline
\end{tabular}

\section{Analysis of the sequence variability}

Our previous analyses of the sequence variability of the 5 'UTR of HCV-1 found a small increase in the variability of cultured HCV compared to patients' HCV RNA [13]. To see if this also applies to cultured HCV-3, we determined the variability of the 314 and $384 \mathrm{HCV}-3$ samples (Table 3).

Shannon entropy is a measure of the number of different genomes in the sample. Genotype 1 and 3 serum and primary samples have approximately the same Shannon entropy (Figure 7A). However, HCV-3 cultured in B-cells and T-cells had lower Shannon entropy than HCV-1, suggesting that particular genomes replicate better in these cells compared to macrophages. We are in the process of determining if longer culturing affects the variability.

Pn is a measure of the number of polymorphic sites in the genome, and is proportional to the number of nucleotide positions that vary in the genome. The genotype 3 serum samples have a greater $P n$ than genotype 1 samples (Figure 7B). However, the HCV-3 primary, B-cell, and Tcell HCV samples have lower Pn than HCV-1 samples. This limited analysis agrees with the Shannon entropy data in that the variability of the cultured HCV-3 is lower than $\mathrm{HCV}-1$.

\section{Distribution of variant bases in isolated $\mathrm{HCV}$ consensus sequences}

We compared HCV RNA from patient 384 serum and four laboratory isolates to determine if changes were consistent with the current $2 \mathrm{D}$ model of the 5'UTR RNA proposed by Honda et al. (2001). The 19 variant bases were either in regions that are not base paired, or where the changes would not affect base pairing (Figure 8). So although there were a number of changes to the sequence after culturing, these did not appear to cause any differences that would affect the overall $2 \mathrm{D}$ structure of this model. All of the differences in the stems had either compensatory changes (e.g. GC to AU at bases 179 and 220) or could use alternative base pairing (e.g., GC to GU at bases 145 and 248). We are not sure how these changes impact the replication of $\mathrm{HCV}$.

\section{Discussion}

There are numerous reports about differences between different strains or types of $\mathrm{HCV}$. We are reporting the isolation and replication of $\mathrm{HCV}$ from patients infected by type 3 strains of HCV. These new isolates can be cultured in both $\mathrm{B}$ and $\mathrm{T}$ cells. By contrast to type 1 strains of $\mathrm{HCV}$, sequence comparisons of the 5 'UTR of $\mathrm{HCV}$ found in patients' sera and their corresponding in vitro 
Table 2: List of samples and PCR conditions in this study.

\begin{tabular}{|c|c|c|c|c|c|c|c|}
\hline Isolate & Cell type & $\begin{array}{c}\text { Date of } \\
\text { transmission }\end{array}$ & $\begin{array}{c}\text { Clones } \\
\text { sequenced }\end{array}$ & $\begin{array}{l}\text { Outer PCR } \\
\text { primers }\end{array}$ & $\begin{array}{l}\text { Outer PCR } \\
\text { Temp. }\end{array}$ & $\begin{array}{l}\text { Inner } \\
\text { primers }\end{array}$ & $\begin{array}{l}\text { Inner } \\
\text { Temp. }\end{array}$ \\
\hline 314 serum & All & $1 / 5 / 05$ & 25 & $9.1 a-9.2 a$ & 55 & $10.1 \mathrm{a}-10.2$ & 60 \\
\hline $314 \mathrm{~T} 1$ & B cell & $1 / 13 / 05$ & 17 & $9.1 a-9.2 a$ & 55 & $10.1 a-10.2$ & 60 \\
\hline $314 \mathrm{~T} 2$ & B cell & $2 / 4 / 05$ & 5 & $9.1 a-9.2 a$ & 55 & $10.1 a-10.2$ & 60 \\
\hline 384 serum & All & $1 / 8 / 08$ & 24 & $\begin{array}{l}8 \text { up-347 } \\
\text { down }\end{array}$ & 50 & $\begin{array}{l}37 \text { up-318 } \\
\text { down }\end{array}$ & 55 \\
\hline 384 primary & Macrophage & $1 / 30 / 08$ & 26 & $\begin{array}{l}8 \text { up-347 } \\
\text { down }\end{array}$ & 55 & $\begin{array}{l}37 \text { up-318 } \\
\text { down }\end{array}$ & 55 \\
\hline 384 P3HR1 & B cell & $1 / 30 / 08$ & 25 & $\begin{array}{l}\text { 9.1a-flap- } \\
\text { 9.2a-flap }\end{array}$ & 50 & $10.1 a-10.2$ & 60 \\
\hline 384 CEM & T cell & $1 / 30 / 08$ & 27 & $\begin{array}{l}8 \text { up-347 } \\
\text { down }\end{array}$ & 50 & $\begin{array}{l}37 \text { up-318 } \\
\text { down }\end{array}$ & 55 \\
\hline $384 \mathrm{CB}$ & Macrophage & $4 / 7 / 08$ & 8 & $\begin{array}{l}8 \text { up-347 } \\
\text { down }\end{array}$ & 55 & $\begin{array}{l}37 \text { up-318 } \\
\text { down }\end{array}$ & 55 \\
\hline 388 serum & All & $9 / 10 / 08$ & 6 & $\begin{array}{l}8 \text { up-347 } \\
\text { down }\end{array}$ & 50 & $\begin{array}{l}37 \text { up-318 } \\
\text { down }\end{array}$ & 60 \\
\hline 388 primary & Macrophage & $9 / 12 / 08$ & 5 & $\begin{array}{l}8 \text { up-347 } \\
\text { down }\end{array}$ & 50 & $\begin{array}{l}37 \text { up-318 } \\
\text { down }\end{array}$ & 60 \\
\hline $388 \mathrm{~T} 1$ & B cell & $9 / 18 / 08$ & 4 & $\begin{array}{l}8 \text { up-347 } \\
\text { down }\end{array}$ & 50 & $\begin{array}{l}37 \text { up-318 } \\
\text { down }\end{array}$ & 60 \\
\hline
\end{tabular}

isolates suggests significant changes in the sequences of type 3 strains. The replication of other HCV genotypes such as 2, 4, 5, and 6 in our system is awaiting studies.

As we have published before, macrophages are important in selecting HCV-1 for replication $[12,16]$. Since these cells are focus of our studies, we would like to name them as cells that are functionally highly phagocytic and cytochemically stain intensely for non-specific esterase. This would include both fixed and free cells such as histiocytes in connective tissue, Kupffer cells of liver, microglial cells of neuronal tissue, dendritic cells of skin, and alveolar macrophages to name a few. The presence of $\mathrm{HCV}$ in monocytes or macrophages has been shown in $\mathrm{HCV}$-infected individuals [17-21]. In addition, like HIV, infected macrophages may act as a reservoir of biologically active, infectious HCV in vivo. Although, we have had some success in isolating $\mathrm{HCV}-3$, the system is not optimal. Other types of macrophages, e.g. Kupffer cells, are probably better for replication of genotype 3 . Results presented here show that we were able to isolate and culture $\mathrm{HCV}$ from patients infected with $\mathrm{HCV}-3$ to a limited extent. However, the HCV-3 produced by macrophages, B-cells, and T-cells were significantly different from HCV-3 in the patients' sera (Figures 3 and 4).

We were unable to find one set of PCR primers and conditions that worked for all of our samples. For genotype 1 , we routinely use the same set of conditions for the analysis of the 5'UTR. For genotype 3, we found that some samples would not work for any particular set of PCR conditions. This is presumably due to a high degree of variability of $\mathrm{HCV}-3$.

Our studies indicate that the macrophages preferentially select $\mathrm{HCV}-1$, making them the dominant virus type (Figure 4), and HCV-3 may poorly infect macrophages from cord blood. The reduced sequence complexity of HCV-3 cultured in B-cells and T-cells suggests 


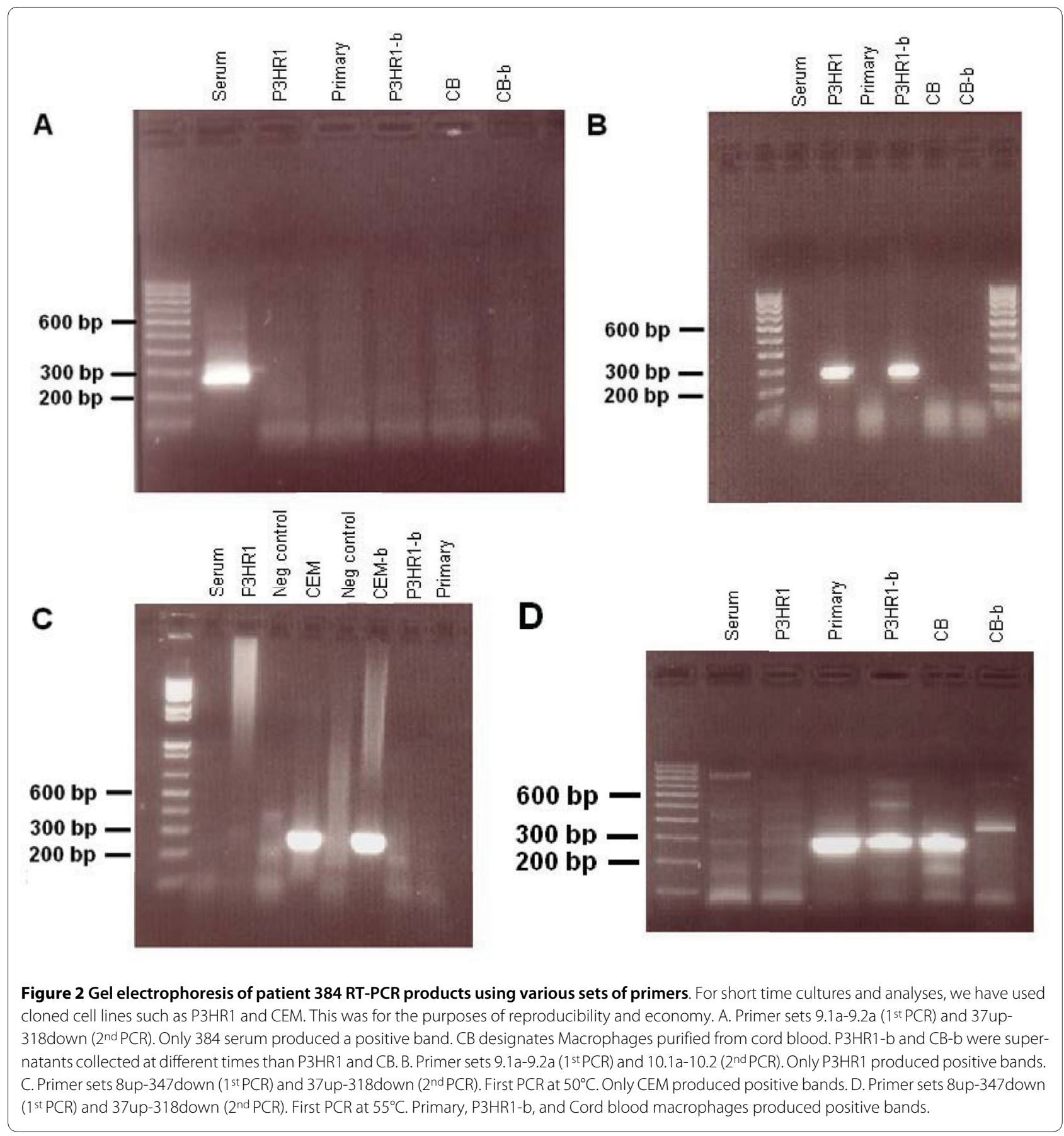

that macrophages are selecting against this genotype. Sera from patients 314 and 384 had HCV-3 sequences, while the $\mathrm{HCV}$ in macrophages and other cell types was only HCV-1.

The 388 T1 sample (B-cells) had 8 C's starting at position 120, compared to 7 for the 388 serum and 388 primary (macrophage) samples. Although we only sequenced four clones for this sample, every one of them had an extra $C$. We have previously observed an additional $\mathrm{C}$ in several HCV-1 samples [13]. In addition, we have found a large deletion in this area for one sample [16]. This region is located between stem-loops II and III, thus apparently allowing greater variability. HCV needs to be infectious, and the level of replication of these infectious agents will depend upon a number of factors, most importantly the target cells.

The results presented here suggest that HCV-3 may need a different cell type for its primary replication in vitro. Our previous publications document the selection of HCV-1 in macrophages or similar cells viz., neuronal 


\begin{tabular}{|c|c|}
\hline \multirow[t]{2}{*}{ Consensus } & AGCGTCTAGCCATGGCGTTAGTATGAGTGTCGTGCAGCCTCCAGGACCCCCCCTCCCGG \\
\hline & 120 \\
\hline & \\
\hline 314 serum & 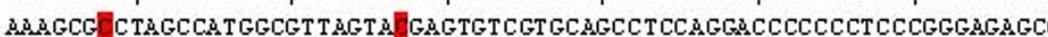 \\
\hline \multirow{3}{*}{$\begin{array}{ll}314 & \mathrm{~T} 1 \\
314 & \mathrm{~T} 2\end{array}$} & \multirow{2}{*}{$\begin{array}{l}\text { A.AGCCGTCTAGCCA TGGCGTT AGTATGAGTGTCGT GCAGCCTCCAGGACCCCCCCTCCCGGGAGAG } \\
\text { AMAGCGTCTAGCCA TGGCGTTAGTATGAGTGTCGT GCAGCCTCCAGGACCCCCCCTCCCGGGAGAG }\end{array}$} \\
\hline & \\
\hline & \multirow{2}{*}{ AMAGCGTCTAGCCATGGCGT TAGTATGAGTGTCGT GCAGCCTCCAGGACCCCCCCTCCCGGGAG } \\
\hline 177 & \\
\hline \multirow[t]{2}{*}{ Consensus } & 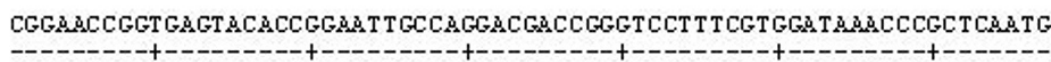 \\
\hline & $151 \quad 160 \quad 170 \quad 180 \quad 190 \quad 100$ \\
\hline & \multirow{2}{*}{ 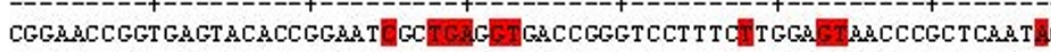 } \\
\hline & \\
\hline \multirow{2}{*}{$314 \mathrm{~T} 2$} & CGGAACCGGT GAGTACACCGGAAT TGCCAGGACGACCGGGTCCT TCGTGGATAAACCCGCTCAAT \\
\hline & CGGAACCGGT GAGTACACCGGAATTGCCAGGACGACCGGGTCCT TTCGTGGATABACCCGCTCAAT \\
\hline 177 & CGGAACCGGTGAGTACACCGGAMTT TCCAGGACGACCGGGTCCT T TCT TGGATAAACCCGCTCA. \\
\hline \multirow[t]{3}{*}{ Consensus } & GCGT GCCCCCGCAAGACCGCT AGCCGAGT AGTGTTGGGTCGCGAHAGGCCTTGTGGTACTGCCT \\
\hline & ++-- \\
\hline & 29025 \\
\hline & CGTGCCCCGC AGA TODCTAGCCGAGTAGTGTTGGGTCGC \\
\hline $314 \mathrm{~T} 1$ & CGTGCCCCCGCAAGACCGCTAGCCGAGTAGT GTTGGGTCGC \\
\hline $314 \mathrm{~T} 2$ & GCGT GCCCCCGCAAGACCGCT AGCCGAGT AGTGTT GGGTCGCGAAGGCCTTGT GGT ACT GCCT \\
\hline & 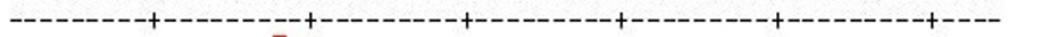 \\
\hline & CGAGTAGTGTTGGGTCGCGHA \\
\hline
\end{tabular}

Figure 3 Comparisons of 5'UTR consensus sequences between patient $\mathbf{3 1 4}$ serum and isolates of HCV. H77, GenBank accession number NC 004102, is shown for comparison purposes and was not used to determine the consensus.

\section{Consensus \\ 384 serum 384 primary 384 CEM 384 P $3 H R 1$ $384 \mathrm{CB}$ H77 Consensus 384 serum 384 primary 384 CEM 384 P3HR1 $384 \mathrm{CB}$ H77

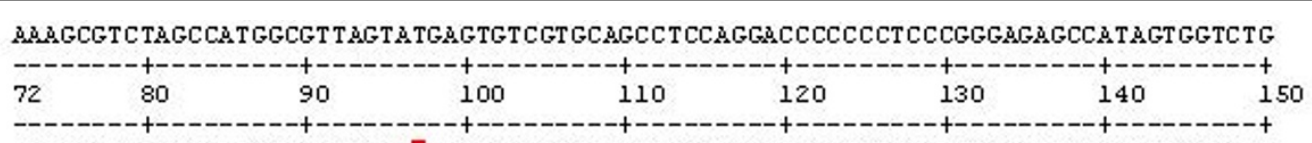 \\ AAAGCGTCTAGCCATGGCGT TAGT A FAGTGTCGTGCAGCCTCCAGGACCCCCCCTCCCGGGAGAGCCATAGTGGTCTG AAAGCGTCTAGCCATGGCGT TAGTATGAGTGTCGT CAGCCTCCAGGACCCCCCCTCCO GGAGAGCCATAGTGGTCTG AMAGCGTCTAGCCA TGGCGT TAGTATGAGTGTCGT CAGCCTCCAGGACCCCCCCTCCCGGGAGAGCCATAGTGGTCTG AHAGCGTCTAGCCATGGCGT TAGTATGAGTGTCGTGCACCCTCCAGGACCCCCCCTCCCGGGACAGCCATAGTGGTCTG AAAGCGTCTAGCCATGGCGT TAGTATGAGTGTCGTGCAGCCTCCAGGACCCCCCCTCCCGGGAGAGCCATAGTGGTCTG

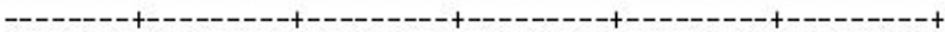 AMAGCGTCTAGCCATGGCGT TAGTATGAGTGTCGTGCAGCCTCCAGGACCCCCCCTCCCGGGAGAGCCATAGTGGTCTG \\ CGGAACCGTGAGTACACCGGAMT TGCCAGGACGACCGGG

\begin{tabular}{|c|c|c|c|c|c|c|c|}
\hline 151 & 160 & 170 & 180 & 190 & 200 & 210 & 220 \\
\hline
\end{tabular}

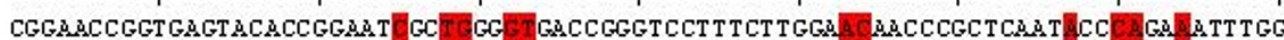 CGGAACCGGT GAGTACACCGGAT T GCCAGGACGACCGGGTCCT T TCT TGGATAMACCCGCT CAATCCCTGGAGATTTGG CGGAACCGGT GAGTACACCGGA T TGCCAGGACGACCGGGTCCT T TCT TGGA TAMACCCGCTCA.ATGCCTGGAGATT TGG CGGAACCGGT GAGTACACCGGAAT T GCCAGGACGACCGGGTCCT T TCT TGGATAAACCCGCTCAATGCCTGGAGATTTGG CGGAACCGGT GAGT ACACCGGA T TCCAGGACGACCGGGTCCT T TCT TGGAT AAACCCGCT CAAT GCCTGGAGATTTGG ----------+----------+----------+----------+---------+----------+----------+----------+ CGGAACCGGT GAGTACACCGGAAT TGCCAGGACGACCGGGTCCT T TCT TGGATAAACCCGCTCAATGCCTGGAGATTTGG} Consensus 384 serum 384 primary 384 CEM 384 P $3 H R 1$ $384 \mathrm{CB}$

H77

GCGTGCCCCCGCAAGACTGCTAGCCGAGTAGTGTTGGGTCGCGAAGGCCTTGTGGTACTGCCT

\begin{tabular}{|c|c|c|c|c|c|c|}
\hline 231 & 240 & 250 & 260 & 270 & 280 & $290 \quad 294$ \\
\hline
\end{tabular}

GCGTGCCCCCGC HAGAFCACTACCCGAGTAGTGTTGGGTCGCGABAGGCCTTGTGGTACTGCCT GCGT GCCCCCGCAAGACTGCT AGCCGAGT AGTGTT GGGTCGCGAASGGCCTTGTGGTACT GCCT GCGT GCCCCCGCAAGACTGCT AGCCGAGT AGTGTT GGGTCGCGAMAGGCCTT GTGGT ACT GCCT GCGT GCCCCCGCAMGACTGCTAGCCGAGTAGTGTTGGGTCGCGAAMGGCCTTGTGGTACTGCCT GCGT GCCCCCGCAAGACTGCT AGCCGAGT AGTGTT GGGTCGCGAMAGGCCTT GT GGT ACT GCCT GCGT GCCCCGCAAGACTGCTAGCCGAGTAGTGTTGGGTCGCGAAGGCCTTGTGGTACT GCCT

Figure 4 Comparisons of 5'UTR consensus sequences between patient 384 serum and isolates of HCV. H77 is shown for comparison purposes and was not used to determine the consensus. 


\begin{tabular}{|c|c|}
\hline \multirow[t]{3}{*}{ Consensus } & 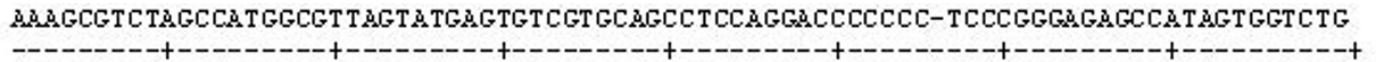 \\
\hline & $\begin{array}{lllll}100 & 110 & 120 & 130 & 140\end{array}$ \\
\hline & \\
\hline 388 serum & 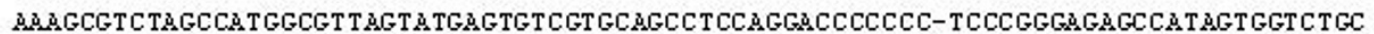 \\
\hline 388 primary & \multirow{2}{*}{ 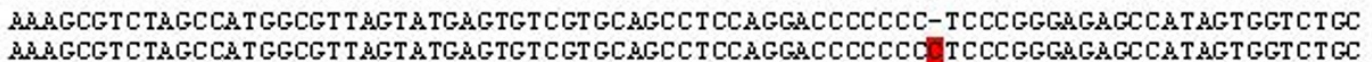 } \\
\hline \multirow[t]{2}{*}{$388 \mathrm{~T} 1$} & \\
\hline & 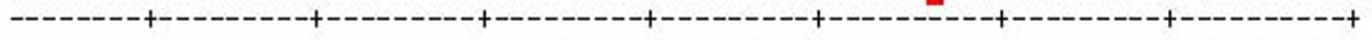 \\
\hline H77 & AMAGCGTCTAGCCATGGCGTTAGTATGAGTGTCGT GCAGCCTCCAGGACCCCCCC-TCCCGGGAGAGCCATAGTGGTCTGC \\
\hline \multirow[t]{4}{*}{ Consensus } & CGGAACCGGT GAGTACACCGGAAT T GCCAGGACGACCGGGTCCT T TCTTGGATAAACCCGCTCAATGCCTGGAGATT TGG \\
\hline & Co \\
\hline & 151 \\
\hline & 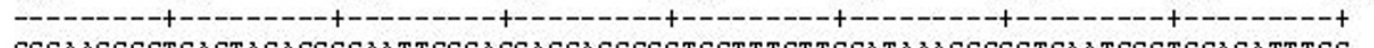 \\
\hline 388 serum & \multirow{3}{*}{ 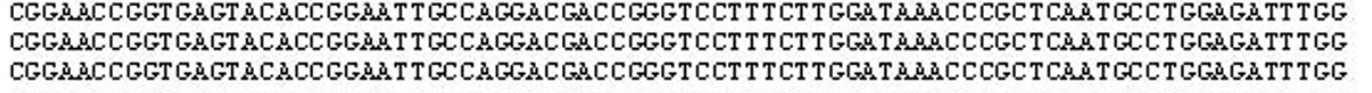 } \\
\hline 388 primary & \\
\hline $388 \mathrm{~T} 1$ & \\
\hline & \multirow{2}{*}{ 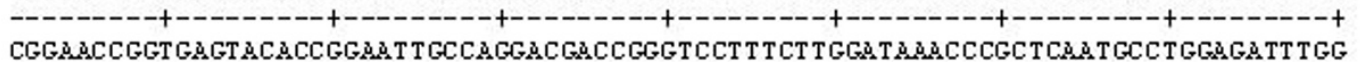 } \\
\hline H77 & \\
\hline \multirow[t]{4}{*}{ Consensus } & GCGTGCCCCCGCAAGACTGCTAGCCGAGT AGTGTTGGGTCGCGAAAGGCCTTGTGGTACTGCCT \\
\hline & 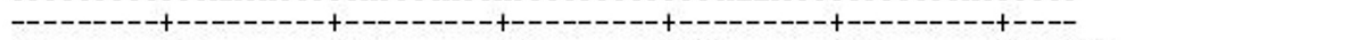 \\
\hline & 290294 \\
\hline & 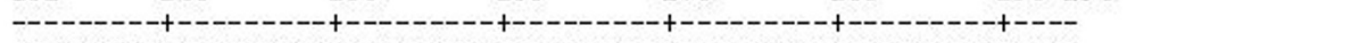 \\
\hline 388 primary & GCGTGCССССGCAAGACTGCT AGCCGAGT AGTGTTGGGTCGCGAAAGGCCTTGTGGTACTGCCT \\
\hline & GCGT GCCCCCGCAAGACTGCT AGCCGAGT AGT GTTGGGTCGCGAAAGGCCTTGTGGTACTGCCT \\
\hline 388 serum & GCGT GCCCCCGCAAGACTGCTAGCCGAGT AGTGTT GGGTCGCGAMAGGCCTTGTGGTACTGCCT \\
\hline & 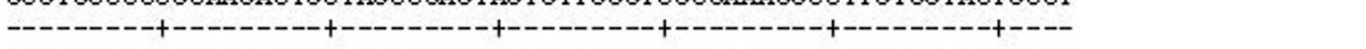 \\
\hline H77 & GCGT GCCCCCGCAAGACTGCTAGCCGAGTAGTGTT GGGTCGCGAMAGGCCTTGT GGTACTGCCT \\
\hline
\end{tabular}

Figure 5 Comparisons of 5'UTR consensus sequences between patient 388 serum and isolates of HCV. H77 is shown for comparison purposes and was not used to determine the consensus.

\begin{tabular}{|c|c|}
\hline & TTAGTACGAGTGTCGTGCAGCCTCCAGGACCCC \\
\hline & 110 \\
\hline & \multirow{2}{*}{ 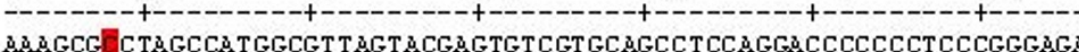 } \\
\hline 314 serum & \\
\hline 384 serum & AAAGCGTCTAGCCATGGCGT TAGTACGAGTGTCGT GCAGCCTCCAGGACCCCCCCTCCCGGGA \\
\hline \multirow[t]{2}{*}{388 serum } & AAAGCGTCTAGCCAT GGCGT TAGT A GAGTGTCGT GCAGCCTCCAGGACCCCCCCTCCCGGGA \\
\hline & 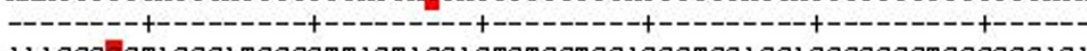 \\
\hline N2L1 & AAAGCGECTAGCCATGGCGT TAGTACGAGTGTCGT GCAGCCTCCAGGACCCCCCCTCCCGGGAG \\
\hline \multirow[t]{2}{*}{ Consensus } & CGGAACCGGT GAGTACACCGGAMTCGCTGGGGTGACCGGGTCCT T TCT TGGA RAACCCGCTCA \\
\hline & $\begin{array}{lllll}160 & 170 & 180 & 190 & 200\end{array}$ \\
\hline & \\
\hline 384 serum & 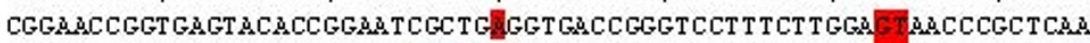 \\
\hline \multirow[t]{2}{*}{388 serum } & \multirow{2}{*}{ 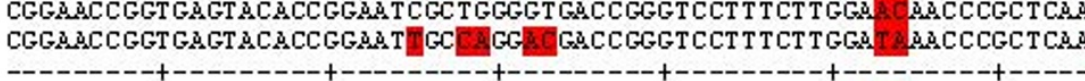 } \\
\hline & \\
\hline NZLl & CGGAACCGGT GAGTACACCGGASTCGCTGGGGTGACCGGGTCCT T TCT TGGA \\
\hline \multirow[t]{4}{*}{ Consensus } & \multirow{2}{*}{ GCGT GCCCCCGCGAGATCACT AGCCGAGT AGTGTT GGGTCGCGAAAGGCCTTGTGGT ACT GCCT } \\
\hline & \\
\hline & $240 \quad 250$ \\
\hline & \multirow{2}{*}{ 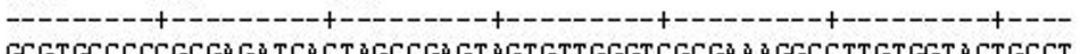 } \\
\hline 314 serum & \\
\hline & 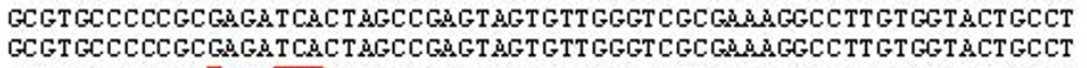 \\
\hline \multirow[t]{2}{*}{388 serum } & GCGTGCCCCCGC \\
\hline & \multirow{2}{*}{ GCGT GCCCCCGCGA GATCACT AGCCGAGTAGT GTT GGGT CGCGA A GGCCTTGT GGTACTGCC } \\
\hline & \\
\hline
\end{tabular}

Figure 6 Comparisons of 5'UTR consensus sequences of sera from patients $\mathbf{3 1 4}, \mathbf{3 8 4}$, and $\mathbf{3 8 8}$. NZL1 is a reference HCV-3 at NCBI Entrez genome (accession number NC_009824), is shown for comparison purposes and was not used to determine the consensus sequence. 
Table 3: Sequence complexity of genotype $3 \mathrm{HCV}$ samples.

\begin{tabular}{lccc}
\hline Sample & Number & Shannon entropy (Sn) & Pn (10-3) \\
\hline 314 serum & 26 & 0.50 & 2.46 \\
\hline 314 T1 & 17 & 0.15 & 0.11 \\
\hline 384 serum & 24 & 0.26 & 2.01 \\
\hline 384 primary & 26 & 0.53 & 0.84 \\
\hline 384 P3HR1 & 25 & 0.26 & 1.05 \\
\hline $\begin{array}{l}384 \text { CEM } \\
\text { Pn variability and Shannon entropy, normalized for the number of samples, were calculated as described by Cabot et al. [27] and Pawlotsky } \\
\text { et al. [28]. }\end{array}$ & & \\
\hline
\end{tabular}

precursors. Individuals infected with genotype 3 may have small amounts of other genotypes circulating in their blood. It is possible that these other genotypes may also prefer to infect specific cell types for replication in vitro. Others have shown that different tissues in one particular individual may harbor different genotypes of $\mathrm{HCV}$ [22-24], suggesting that cell tropism may establish the tissue specificity of $\mathrm{HCV}$ in infected individuals. Variability in diseases of HCV-infected individuals, such as neuropathy and lymphoma, may either be due to variations in the virus or to increased susceptibility of infected cell types, or the presence of other viral agents in circulation. This phenomenon is under further investigation.

\section{Methods}

\section{Patient samples}

All patient samples were given a code at the source, and a sequential number in our laboratory to preserve their anonymity. Patients 314, 384, and 388 were all AIDS patients doubly infected with HIV and HCV. The HCV was genotyped as type 3 using an INNO-LiPA assay by a clinical testing laboratory (Quest Diagnostics).

\section{In vitro culture system}

Our culture system, described earlier, takes advantage of the infectious particles present in the peripheral circulation [12]. Briefly, the isolation of HCV was done in two stages: (A) HCV derived from patients' blood was used to infect human macrophages; (B) HCV obtained from the macrophages was then used to infect freshly transformed B-cells or T-cells obtained from human fetal cord blood and cultured in the presence of 100 units/ml of IL-2 (Collaborative Biomedical Products, catalog number 40121). The types of samples that were analyzed included: (i) $\mathrm{HCV}$ found in serum or plasma of patients; (ii) HCV pro- duced by macrophages (primary isolate); and (iii) HCV produced by B-cells or T-cells (secondary isolates). Each sample was given a unique number that indicated the patient and a suffix designating replication into various cell types. Transfers into fresh uninfected B-cells were given a suffix of $\mathrm{T} 1$, transfers into cell lines, such as P3HR1 and CEM, were given a suffix of the cell line name, and secondary transfers into macrophages produced from human cord blood (CB). All isolates were produced in the laboratories at CIMM, and are therefore called CIMM-HCV. The data in this paper is based on these isolates.

CEM.NCI and CEM.SS cells were obtained through the NIH AIDS Research and Reference Reagent Program, Division of AIDS, NIAID, NIH. P3HR1 cells were obtained from ATCC. The cell types were cultured using the methods recommended by ATCC. Single cell clones were established from these cell lines for the sake of uniformity of data and the removal of adventitious material such as mycoplasma.

\section{RT-PCR}

RNA was purified using TriReagent as previously described [12], and a nested RT-PCR was performed. For the patient 314 samples, the procedure was as previously described using Fidelitaq (US Biochemicals) [12]. For the other patient samples, $\mathrm{RT}$ was performed using $\mathrm{N}_{12}$ random primers for 1212 -minute cycles at $48^{\circ} \mathrm{C}$ using cyclic RT (Bioneer). The PCR was performed using Bioneer high fidelity TLA PCR premixes. The primers used for the experiments are listed in Table 1.

For each TLA PCR reaction, samples were denatured at $94^{\circ} \mathrm{C}$ for 3 minutes, and then 30 cycles of amplification were performed with the following temperature profiles: $94^{\circ} \mathrm{C}$ for 30 seconds, 50 or $55^{\circ} \mathrm{C}$ for 30 seconds, and $72^{\circ} \mathrm{C}$ 


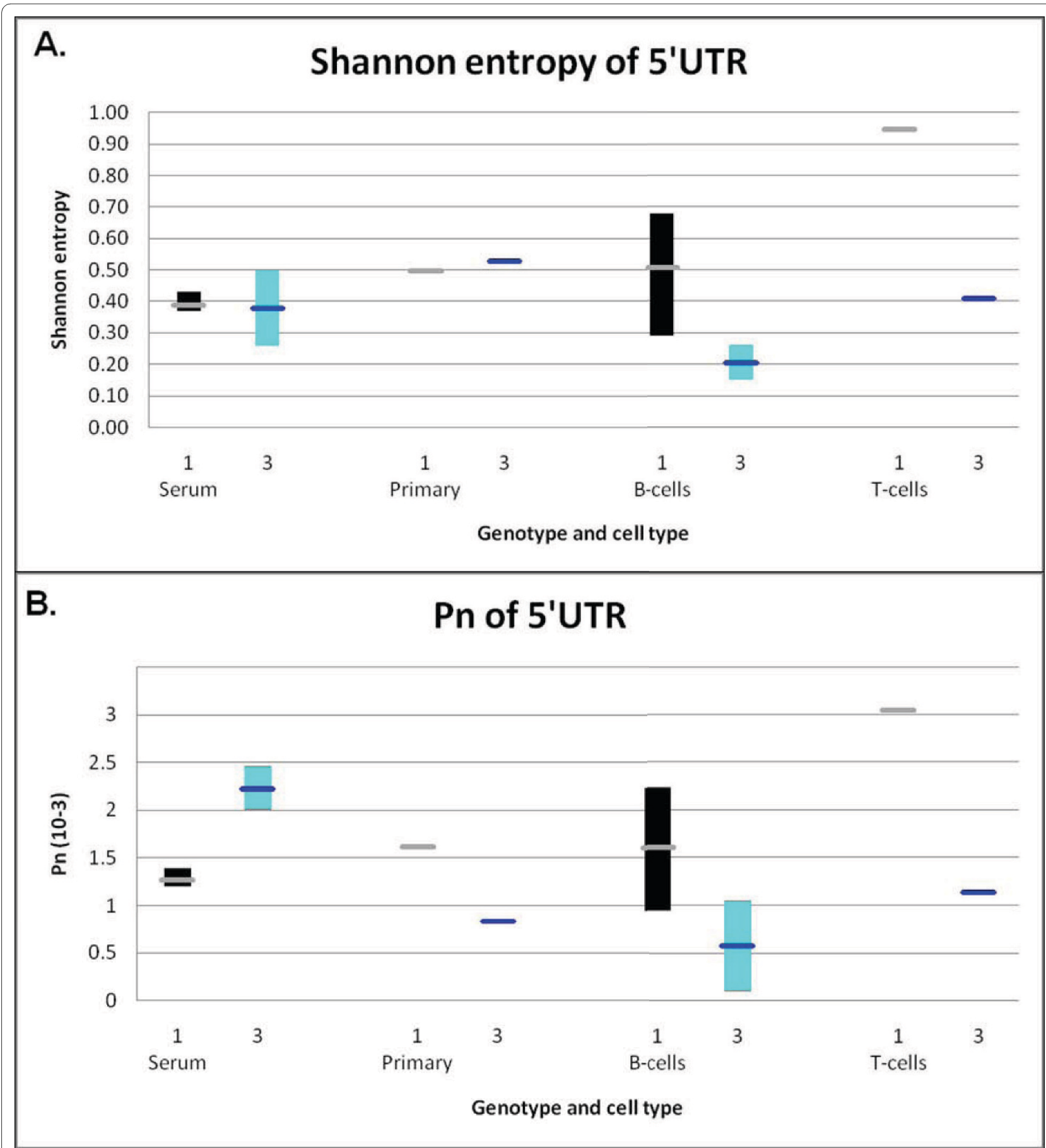

Figure 7 Sequence complexity of genotype 3 HCV samples. (A) Shannon entropy comparisons of genotypes 1 and 3 HCV cultured in various cell types. (B) The Pn variability of genotype 1 and 3 HCV cultured in various cell types. The genotype 1 values are from Revie et al. [13]. The ranges are indicated by vertical bars and the means by thick horizontal lines.

for $1 \mathrm{~min}$ for the outer primer set and $94^{\circ} \mathrm{C}$ for $30 \mathrm{sec}$ onds, 55 or $60^{\circ} \mathrm{C}$ for 30 seconds, and $72^{\circ} \mathrm{C}$ for $1 \mathrm{~min}$ for the inner primer set (Table 2). Normally, $2 \mathrm{ml}$ of RNA was used for the RT, $2 \mathrm{ml}$ of the cDNA used for the first PCR, and $2 \mathrm{ml}$ of the first PCR product for the second PCR. Volumes were adjusted as needed.

\section{Sequencing}

Fragments comprising approximately 263 or 276 bp of the 5'UTR generated by nested PCR were cloned using Invitrogen's ZeroBlunt cloning kit. Plasmid DNA from a minimum of 4 clones of each sample were amplified by Templiphi (Amersham) and then sequenced using a 
Beckman CEQ8000 Genetic Analysis system. In order to ensure high quality analyses, only clones that had identical sequences for both strands were analyzed. All methods followed the manufacturers' protocols.

\section{Bioinformatics}

Analysis of the sequences was performed as described previously [13]. The numbers for the base positions that are reported here are the bases compared to the positions of the full length genome of HCV H77 [25,26].

Complexity of the variation was calculated as Shannon entropy and Pn complexity as described previously [13]. Only samples with at least 17 sequences were analyzed for variation.
Accession numbers of HCV sequences used for genotyping The 5' UTR sequences reported in the paper have the GenBank accession numbers $\underline{\text { HM641722 }}$ to $\underline{\text { HM641732. }}$.

\section{Competing interests}

All intellectual rights are reserved by the California Institute of Molecular Medicine (CIMM). There are no competing interests between California Lutheran University or any other body and CIMM.

\section{Authors' contributions}

SZS performed the biological work. JGP and ASK performed the clinical work, recruitment of patients, and procurement of specimens. MOA designed experiments and performed molecular work. SZS and DR designed and conducted experiments, analyzed the data, and wrote the manuscript. All of the authors have read and approved the final manuscript. 


\section{Acknowledgements}

We wish to thank Renu Grewal and Herbinder Grewal for their technical assistance.

\section{Author Details}

'Department of Biology, California Lutheran University, Thousand Oaks, California, USA, 2Ventura County Medical Center, Ventura, California, USA ${ }^{3}$ Ventura County Hematology-Oncology Specialists, Oxnard, CA, USA, ${ }^{4}$ California Institute of Molecular Medicine, Ventura, California, USA and ${ }^{5}$ Division of Human Gene Therapy, Department of Medicine, University of Alabama at Birmingham, Birmingham, AL, USA

Received: 13 May 2010 Accepted: 13 July 2010

Published: 13 July 2010

\section{References}

1. Rustgi VK: The epidemiology of hepatitis C infection in the United States. J Gastroenterol 2007, 42:513-521.

2. Mangia A, Cascavilla I, Lezzi G, Spirito F, Maertens G, Parlatore L, Saracco G, Rizzetto M, Andriulli A: HCV genotypes in patients with liver disease of different stages and severity. J Hepatol 1997, 26:1173-1178.

3. NIH Consensus Statement on Management of Hepatitis C: 2002. NIH Consens State Sci Statements 2002, 19:1-46.

4. Tarantino G, Craxi A: Optimizing the treatment of chronic hepatitis due to hepatitis C virus genotypes 2 and 3: a review. Liver Int 2009, 29(Suppl 1):31-38.

5. Weigand K, Stremmel W, Encke J: Treatment of hepatitis C virus infection. World J Gastroenterol 2007, 13:1897-1905.

6. Asselah T, Rubbia-Brandt L, Marcellin P, Negro F: Steatosis in chronic hepatitis C: why does it really matter? Gut 2006, 55:123-130.

7. Bochud PY, Cai T, Overbeck K, Bochud M, Dufour JF, Mullhaupt B, Borovicka J, Heim M, Moradpour D, Cerny A, et al.: Genotype 3 is associated with accelerated fibrosis progression in chronic hepatitis $C$. J Hepatol 2009, 51(4):655-66.

8. Salahuddin SZ, Snyder KA, Godwin A, Grewal R, Prichard JG, Kelley AS, Revie D: The simultaneous presence and expression of human hepatitis $C$ virus (HCV), human herpesvirus-6 (HHV-6), and human immunodeficiency virus-1 (HIV-1) in a single human T-cell. Virol J 2007, 4:106

9. Friebe $\mathrm{P}$, Lohmann V, Krieger N, Bartenschlager R: Sequences in the $5^{\prime}$ nontranslated region of hepatitis $C$ virus required for RNA replication. J Virol 2001, 75:12047-12057.

10. Rijnbrand R, Bredenbeek $P$, van der Straaten $T$, Whetter $L$, Inchauspe $G$, Lemon S, Spaan W: Almost the entire 5 ' non-translated region of hepatitis $C$ virus is required for cap-independent translation. FEBS Lett 1995, 365:115-119.

11. Wang C, Sarnow P, Siddiqui A: Translation of human hepatitis $C$ virus RNA in cultured cells is mediated by an internal ribosome-binding mechanism. J Virol 1993, 67:3338-3344.

12. Revie D, Braich RS, Bayles D, Chelyapov N, Khan R, Geer C, Reisman R, Kelley AS, Prichard JG, Salahuddin SZ: Transmission of human hepatitis C virus from patients in secondary cells for long term culture. Virol J 2005 , 2:37.

13. Revie D, Alberti MO, Braich RS, Chelyapov N, Bayles D, Prichard JG, Salahuddin SZ: Analysis of in vitro replicated human hepatitis $C$ virus (HCV) for the determination of genotypes and quasispecies. Virol J 2006, 3:81.

14. Barria MI, Gonzalez A, Vera-Otarola J, Leon U, Vollrath V, Marsac D, Monasterio O, Perez-Acle T, Soza A, Lopez-Lastra M: Analysis of natural variants of the hepatitis $C$ virus internal ribosome entry site reveals that primary sequence plays a key role in cap-independent translation. Nucleic Acids Res 2009, 37:957-971.

15. Masante C, Mahias K, Lourenco S, Dumas E, Cahour A, Trimoulet P, Fleury $H$, Astier-Gin T, Ventura M: Seven nucleotide changes characteristic of the hepatitis $C$ virus genotype $35^{\prime}$ untranslated region: correlation with reduced in vitro replication. J Gen Virol 2008, 89:212-221.

16. Revie D, Alberti MO, Braich RS, Bayles D, Prichard JG, Salahuddin SZ: Discovery of significant variants containing large deletions in the 5'UTR of human hepatitis C virus (HCV). Virol J 2006, 3:82.
17. Chang TT, Young KC, Yang YJ, Lei HY, Wu HL: Hepatitis C virus RNA in peripheral blood mononuclear cells: comparing acute and chronic hepatitis C virus infection. Hepatology 1996, 23:977-981.

18. Muratori L, Gibellini D, Lenzi M, Cataleta M, Muratori P, Morelli MC, Bianchi FB: Quantification of hepatitis $C$ virus-infected peripheral blood mononuclear cells by in situ reverse transcriptase-polymerase chain reaction. Blood 1996, 88:2768-2774.

19. Blackard JT, Kemmer N, Sherman KE: Extrahepatic replication of HCV: insights into clinical manifestations and biological consequences. Hepatology 2006, 44:15-22.

20. Kaiser P, Niederost B, Joos B, von Wyl V, Opravil M, Weber R, Gunthard HF, Fischer M: Equal amounts of intracellular and virion-enclosed hepatitis $C$ virus RNA are associated with peripheral-blood mononuclear cells in vivo. J Infect Dis 2006, 194:1713-1723.

21. Laskus T, Operskalski EA, Radkowski M, Wilkinson J, Mack WJ, deGiacomo M, Al-Harthi L, Chen Z, Xu J, Kovacs A: Negative-strand hepatitis C virus (HCV) RNA in peripheral blood mononuclear cells from anti-HCVpositive/HIV-infected women. J Infect Dis 2007, 195:124-133.

22. Bagaglio S, Cinque P, Racca S, Pedale R, Grasso MA, Lazzarin A, Morsica G Hepatitis $C$ virus populations in the plasma, peripheral blood mononuclear cells and cerebrospinal fluid of HIV/hepatitis C virus-coinfected patients. Aids 2005, 19(Suppl 3):S151-165.

23. Roque-Afonso AM, Ducoulombier D, Di Liberto G, Kara R, Gigou M, Dussaix E, Samuel D, Feray C: Compartmentalization of hepatitis C virus genotypes between plasma and peripheral blood mononuclear cells. J Virol 2005, 79:6349-6357.

24. Li H, Thomassen LV, Majid A, McMahon BJ, Bruden D, McArdle S, Bano N, Chung M, Carithers RL, Perkins JD, et al:: Investigation of putative multisubtype hepatitis $C$ virus infections in vivo by heteroduplex mobility analysis of core/envelope subgenomes. J Virol 2008, 82:7524-7532.

25. Kuiken C, Combet C, Bukh J, Shin IT, Deleage G, Mizokami M, Richardson R, Sablon E, Yusim K, Pawlotsky JM, Simmonds P: A comprehensive system for consistent numbering of HCV sequences, proteins and epitopes. Hepatology 2006, 44:1355-1361.

26. Kuiken C, Yusim K, Boykin L, Richardson R: The Los Alamos HCV Sequence Database. Bioinformatics 2005, 21:379-384

27. Cabot B, Martell M, Esteban J, Sauleda S, Otero T, Esteban R, Guardia J, Gomez J: Nucleotide and amino acid complexity of hepatitis $C$ virus quasispecies in serum and liver. J Virol 2000, 74:805-811.

28. Pawlotsky J, Germanidis G, Neumann A, Pellerin M, Frainais P, Dhumeaux $D$ : Interferon resistance of hepatitis $C$ virus genotype $1 \mathrm{~b}$ : relationship to nonstructural 5A gene quasispecies mutations. J Virol 1998, 72:2795-2805.

29. Lyons A, Lytle J, Gomez J, Robertson H: Hepatitis C virus internal ribosome entry site RNA contains a tertiary structural element in a functional domain of stem-loop II. Nucleic Acids Res 2001, 29:2535-2541.

doi: $10.1186 / 1743-422 X-7-155$

Cite this article as: Revie et al., Analysis of the 5'UTR of HCV genotype 3 grown in vitro in human B cells, T cells, and macrophages Virology Journal 2010, 7:155

\section{Submit your next manuscript to BioMed Central and take full advantage of:}

- Convenient online submission

- Thorough peer review

- No space constraints or color figure charges

- Immediate publication on acceptance

- Inclusion in PubMed, CAS, Scopus and Google Scholar

- Research which is freely available for redistribution 